\title{
Facilitating student engagement in online discussions through self-organisation
}

\author{
Elena Ončevska Ager \\ Saints Cyril and Methodius University in Skopje, North Macedonia
}

Keywords: student engagement; self-organised learning; online learning; teacher education; motivation; positive psychology; Covid-19

\section{The challenge}

As a teacher educator at a university in North Macedonia - a small, developing European country - I provide initial teacher training to pre-service teachers (PSTs) of English as a foreign language. This involves observing and discussing, in small groups, lessons delivered by the PSTs in actual school contexts. The PSTs share any salient moments from the lesson (for example, a student misbehaving) and seek to understand the chosen classroom episode more fully by using relevant literature to support their arguments. My role is to moderate the discussion, joining in only when needed. Developing informed reflection skills, however, relies on active involvement on the part of the PSTs, rather than merely attending sessions and taking notes, as the PSTs have suggested they are accustomed to on other modules. I find myself, therefore, needing to work against the established institutional culture to get the PSTs actively involved in their own learning.

Student passivity has always been an issue in my teacher education classroom, with only a few (out of 10-15) PSTs regularly taking part in the course discussions and projects. This is despite course participation directly feeding into their course mark. Covid-19 further exacerbated student passivity as teaching and learning moved online. PSTs were increasingly reluctant to take the floor, perhaps also due to the not very obvious turn-taking norms online sometimes resulting in awkward silences. This was coupled with most PSTs choosing not to turn their video camera on, which took away the little body language that 
online teaching makes available in the first place. Some PSTs were not responsive even when called upon. I felt I needed to take action to help my PSTs engage.

\section{The response}

My first point of reference was the literature on motivation and positive psychology. Ryan and Deci's (2000) self-determination theory posits that motivated behaviour relies on meeting three basic psychological needs: competence (being able to experience success when dealing with the environment), autonomy (a sense that one is granted freedom to interact with the environment) and relatedness (a sense of being connected to other people in one's environment). Positive psychology defines wellbeing as comprising five aspects: positive emotions, involvement in what we do, relationships with other people, the meaning we take from life and a sense of accomplishment in life (Seligman, 2011). Putting these two theories side by side, there seemed to be a strong underlying motif: motivation and happiness, more generally, seem to depend on the success resulting from our active, autonomous involvement with the tasks and with the people in our lives.

How does one encourage student involvement in online academic discussions so as not to rely on PST self-selection? Holec (1981) suggests that students can exercise autonomy regarding various aspects of the course: its aims, content, methodologies and assessment. I decided to tweak the course methodologies so as to make less room for myself on the course, and more for the PSTs, by giving them autonomy in moderating some of our sessions. I later became aware of engaging students through partnerships (Healey et al., 2014), not only with regard to what goes on in the classroom, but also beyond it, for example, in curriculum design and our own research projects.

I invited a PST group who appeared bonded and mature enough to self-organise to moderate their own discussion in the way I moderate it for them; this time, however, I would not be present at all in the virtual room. They enthusiastically embraced the challenge, recorded and shared their session. Watching their session, I found it refreshing to see the group visibly more talkative than usual, laughing, using colloquialisms and a relaxed body language. Most of the PSTs took part in the discussion, even the shyest 
ones, whom I seldom (if ever) hear in class. The silences between the PSTs' turns appeared less uncomfortable than in our regular sessions. I was very pleased to see them discuss most of the points that I would have liked to see raised. Once I reviewed their session, I shared my comments on their work with them, encouraging group reflection on the experience. The students appeared to welcome the change in the format of moderation, suggesting that they would be happy to adopt it again. Some were concerned about their informal communication, even though I do not insist on any formality in my sessions. Others were concerned about the absence of a formal discussion moderator; however, it was apparent to me that one or two PSTs had spontaneously assumed that role, and quite successfully.

Not all the groups I approached with a suggestion to self-organise were as enthusiastic, though. To make sure they were not stressed by the prospect, I offered a "weaker" form of student involvement to them. I delegated tasks before the session and assigned different students to moderate different parts of the groups' discussions, with me acting as:

(a) a student, joining in the discussion as and when, making suggestions and/or comments.

(b) an observer, taking notes during the discussion and joining in at the end of the session or, if time was short, sharing my comments at a later date.

These PSTs, too, welcomed the change in discussion format and suggested they would be interested in further explorations of self-organised learning. My PSTs got to experience first-hand the challenge of dealing with long silences and blank screens in online discussions - an experience which has the potential to help them re-think their own communication choices and perhaps develop empathy for and/or solidarity with the teacher educator.

\section{Recommendations}

Self-organisation is easily adaptable to a range of educational contexts as it does not require any special provisions. My experiments with it suggest that my PSTs were able 
and, depending on group maturity, willing to engage in different forms of self-organised learning, thus tapping into important motivational and wellbeing resources. While I only made changes to my course methodologies, there is scope for student involvement at other course levels (for example, aims, content and/or assessment) as well as beyond the course (for example, curriculum development and/or research). It is worth consulting students about their preferred levels of involvement; they appreciate the trust and the ensuing responsibility that drive self-organised learning, which is hopefully more enjoyable and longer lasting.

\section{References}

Healey, M., Flint, A. and Harrington, K. (2014). Engagement through partnership: students as partners in learning and teaching in higher education. York: The Higher Education Academy.

Holec, H. (1981) Autonomy and foreign language learning. Oxford: Pergamon.

Ryan, R. M. and Deci, E. L. (2000) 'Self-determination theory and the facilitation of intrinsic motivation, social development, and well-being', American Psychologist. 55 (1), 6878. Available at: https://psycnet.apa.org/doi/10.1037/0003-066X.55.1.68 (Accessed: 10 August 2021).

Seligman, M. (2011) Flourish. London: Nicholas Brealey.

\section{Author details}

Elena Ončevska Ager is Associate Professor at Saints Cyril and Methodius University, North Macedonia. She teaches language teacher education courses, and her research interests include mentoring, motivation, professional wellbeing and teacher/learner agency. 